\title{
0 relato de história de vida à luz do pensamento de Walter Benjamin: contribuições aos estudos de identidade
}

\author{
Alfredo César da Veiga* (1) \\ Cecília Pescatore Alves (i)
}

\author{
Pontifícia Universidade Católica de São Paulo, Psicologia Social, São Paulo, SP, Brasil
}

\begin{abstract}
Resumo: O relato de história de vida não é, como muitos pensam, uma metodologia de fácil aplicação, pelo menos em se levando em consideração o pensamento de Walter Benjamin, para quem a história não é simples relato de fatos, mas um encadeamento de experiências que nem sempre podem ser expressas sem correr riscos que, em grande medida, prejudicam ou violentam a consciência do indivíduo que faz do relato um meio para encontrar "redenção" (Erlösung) de experiências do passado marcadas de sofrimentos. Acrescente-se a isso o fato de que, segundo o autor, com a modernidade, perdeu-se a capacidade tanto de contar quanto de ouvir experiências de vida. O texto trabalha essas questões, além de buscar contribuir com os estudos sobre identidade, na perspectiva da psicologia social crítica, que utiliza o método de relato de história de vida.
\end{abstract}

Palavras-chave: memória, experiência, redenção, identidade.

\section{Introdução e discussão metodológica}

Os estudos elaborados, na perspectiva da psicologia social crítica, por Ciampa (1987) introduziram a compreensão sobre identidade como um processo contínuo de metamorfose ao longo da vida do sujeito. O referido autor considera que a dinâmica do processo da identidade ocorre em uma relação dialética do individual com o coletivo. Estes estudos têm sido construídos a partir de pesquisas empíricas em que a narrativa do sujeito, sobre sua história e seu projeto de futuro, ganha destaque por se considerar que o sujeito que narra manifesta na singularidade a pluralidade social. É possível, ainda, identificar o sentido que o narrador atribuiu às relações vividas com a diversidade de pessoas e grupos, e como tais relações possibilitam mudanças na constituição da identidade.

A partir dessas considerações, esta reflexão se propõe a relevar alguns aportes teóricos do filósofo Walter Benjamin sobre narrativas, a fim de adensar a compreensão sobre uma metodologia que vem sendo muito utilizada nas pesquisas de psicologia Social, que são as narrativas de história de vida ${ }^{1}$. Trata-se de uma metodologia qualitativa biográfica "na qual o pesquisador escuta, por meio de várias entrevistas não diretivas, gravadas ou não, o relato da história de vida de alguém" (Nogueira, Barros, Araujo, \& Pimenta, 2017, pp. 466-485).

* Endereço para correspondência: csrveiga2000@gmail.com

1 No texto, usaremos "narrativa" de história de vida; em outros momentos, "relatos" de história de vida. O primeiro termo está mais relacionado ao mundo subjetivo do sujeito que narra, como as emoções e sensações por trás da narrativa. $\mathrm{O}$ "relato" se refere à história que o sujeito conta, em seu aspecto de sujeito que expressa, por meio de palavras e de maneira objetiva, os acontecimentos.
O método tem se revelado eficaz por principalmente possibilitar ao pesquisador um efetivo contato com diferentes memórias, favorecendo um diálogo interior do sujeito consigo próprio (Maccali, Minghini, Walger, \& Roglio, 2013). Entendemos que Walter Benjamin, atento às transformações da experiência moderna e da cultura capitalista e, por conseguinte, das fantasmagorias que esse sistema produz, pode fortalecer a compreensão desse método, uma vez que se trata, em última análise, de ouvir o flâneur contemporâneo que, como aquele dos tempos modernos, se vê igualmente apoderado pela embriaguez "das seduções das lojas" (Benjamin, 2006, p. 462, M 1,3), ou da mercadoria como fetiche, mas que, por outro lado, apesar dessa "embriaguez anamnésica", apodera-se, ao mesmo tempo, "do simples saber, de dados inertes, como de algo experienciado e vivido" que se transmite oralmente, de pessoa para pessoa (Benjamin, 2006, p. 462, M 1,5).

A narrativa de história de vida não se confunde com a pesquisa em história oral, quando utilizada pelos pesquisadores apenas como fontes de dados "para a compreensão do passado, ao lado de documentos escritos, imagens e outros tipos de registro"2.

Por outro lado, a história oral também é vista como um método de investigação que elabora análises qualitativas de processos históricos sociais a partir da visão e versão do ator social, que se expressa por meio de uma estrutura de linguagem repleta de significados sociais e historicamente construídos. Segundo Camargo (1994), esse método possibilita a compreensão de fatos e fenômenos sociais não visíveis a uma mera observação

2 Recuperado de https://cpdoc.fgv.br/acervo/historiaoral 
de fatos, ou mesmo em dados estatísticos, na medida em que se percebem emoções, comportamentos e valores na dinâmica do relato.

Nos estudos sobre identidade humana entendida como um processo contínuo de metamorfose, na narrativa de história de vida, busca-se "um caminho no qual os significados e sentidos são relacionados, fazendo emergir a metamorfose através da qual se constitui o processo da identidade" (Alves, 2017, p. 40).

Dessa forma, não é tão importante o fato relatado pelo depoente, mas a maneira como reagiu a ela, o quanto se deixou afetar por essa mesma história; os não-ditos são tão imprescindíveis quanto os eventos acessados pela memória, com mais destaque para a subjetividade do que à objetividade dos fatos e, sobretudo, a narrativa "pode ser considerada como um processo de produção, de tal forma que a identidade passe a ser entendida como um processo de identificação" (Ciampa, 1987, p. 65).

Cabe destaque a outro ponto, em relação ao método de história oral: a concepção sobre memória. Hobsbawm (1997), escrevendo sobre o método historiográfico, afirma que a história se afastou da narrativa e da ênfase no singular e individual para o estabelecimento de regularidades e a generalização, desprezando o "jeito antigo" de fazer história, ao tempo em que "puxava" os fatos pela memória. Ora, o método de narrativa de história de vida se constrói através desse "jeito antigo", valorizando a memória, como faz essa concepção de história oral, mas com uma aproximação bastante diversa, a começar pela relação que se estabelece com aquele que faz o relato.

Esse sujeito, para a ciência histórica, de maneira geral, é fonte e é também material para a construção de conhecimento e se, porventura, o historiador tiver outro tipo de fonte que responda mais diretamente às suas perguntas, pode abrir mão da história oral ${ }^{3}$. Até mesmo a escola dos Annales que, segundo Le Goff (2001), ao se voltar para a história da vida cotidiana, interessando-se pelos pequenos detalhes da vida ordinária, não tinha outro interesse senão o de abordar a história econômica e social, concebendo, portanto, a vida cotidiana apenas "como o cenário da grande história" (p. 130).

Contrariamente, a história de vida à qual se refere este texto, é aquela em que o relato da cotidianidade, marcado pelas lutas e vontade de superação, não é apreendido apenas como memória de acontecimentos deixados em algum lugar do passado, mas um outro, compreendido no sentido benjaminiano, impregnado de vivência, experiência e movido pelo sentido dialético empregado pelo autor: de ruptura com um estado de coisas que impede de continuar em frente, de fazer de

3 Segundo Alberti (1996), a história oral "não é solução para tudo" e continua afirmando ter "uma forte convicção de que, na história oral como em qualquer outra prática científica, devemos, digamos assim, evitar o desperdício. O que quero dizer com isso? Que só se deve recorrer à metodologia da história oral quando os resultados puderem efetivamente responder às nossas perguntas e quando não houver outro tipo de fonte disponivel" (p. 1-12, grifo nosso). maneira diferente, de forma criativa e revolucionária. Acreditamos que essas e outras percepções de Benjamin enriquecerão o método de narrativa de história de vida e projeto de futuro utilizado nos estudos de identidade.

Outras discrepâncias poderiam ser apontadas, como o modelo de análise da história oral que requer a presença de alguns elementos que ajudem a testificar a verdade dos fatos. Com essa intenção, a história oral precisa construir um eixo diacrônico no qual devem se ancorar as narrativas. Segundo Antônio Santos (2005), "nos depoimentos, a citação de datas, locais, acontecimentos de domínio público e personalidades públicas permitem uma leitura conjunta e a construção de um contexto pelo qual transitam entrevistados e suas lembranças" (p. 1-11).

A narrativa de história de vida, por outro lado, não se ocupa com a "construção de contextos" a partir da fala do narrador, tampouco procura atestar a verdade dos fatos, comparando-os com outros documentos ou mesmo com outras narrativas. De fato, como lembra Butler (2017), "contar uma história sobre si não é o mesmo que dar um relato de si” (p. 22). No relato as palavras podem ser até dispensadas, pois - continua Butler -, mesmo quando o sujeito se recusa a narrar, não deixa, mesmo assim, de se relacionar com a cena de interpelação.

Portanto, apesar de partilharem alguns pontos comuns, como a importância que se dá à linguagem, as discrepâncias aumentam quando se trata de apreender os significados de cada uma dessas abordagens. Só para ficar nesse exemplo, a linguagem, para o método de narrativa de história de vida, abarca também as emoções e os afetos, os sonhos e a imaginação, que em geral pouca coisa acrescentam ao historiador, interessado na trama dos acontecimentos que testificarão (ou não) a verdade dos fatos.

\section{Walter Benjamin}

Walter Benjamin (1892-1940) foi um pensador incomum, não apenas pela originalidade em desenvolver temas tão diversos das mais variadas disciplinas, mas, sobretudo, por ser possuidor daqueles raros talentos que conseguem extrair, dos acontecimentos ordinários, uma variedade de significados sempre inéditos e surpreendentes. Sua originalidade se destaca ainda mais por conseguir ver algo que ninguém antes dele ousava ver, como quando identifica, na obra de arte, uma "aura" que a distingue em unicidade e singularidade. (Benjamin, 1994).

Sobre Walter Benjamin, escreveram destacadas figuras, como Bertold Brecht, que teria dito com pesar ao saber de sua morte que esse seria, de fato, o primeiro dos danos causados por Hitler e, juntamente com sua morte, condenaria também à morte a melhor parte da literatura alemã. Hannah Arendt (1968), ao escrever a introdução da versão de 1968 do livro Illuminations, de Walter Benjamin, afirma que o crítico, como um alquimista, praticava a "obscura arte de transmutar elementos insignificantes 
do real em ouro sólido e brilhante da verdade" (p. 5) e que, ao interpretar os processos históricos, fazia surgir alguma coisa como uma "transfiguração mágica" dos acontecimentos cotidianos.

Estudiosos e pesquisadores de diversas áreas, como filosofia, sociologia, literatura, história e crítica de arte, inspiraram-se em Benjamin a fim de buscar fundamentação teórica para suas pesquisas. $\mathrm{O}$ fato de o autor se mostrar arredio a qualquer tentativa de identificá-lo com alguma disciplina em particular seria, provavelmente, a principal razão para a abrangência de seu pensamento. Benjamin não é um estudioso de ideias, mas da experiência em sua forma material, emocional, visual, psicológica e/ou estética (Pusca, 2009). Seus conceitos não são abstrações metafísicas, mas fundamentam suas estruturas nas experiências históricas concretas (Löwy, 2005). A universalidade do pensamento benjaminiano abre possibilidades imprescindíveis para estudar a história dos vencidos e oprimidos não só no contexto dos eventos das grandes guerras, mas até mesmo de populações inteiras da América Latina, com seu histórico de espoliação e opressão.

Os objetos ${ }^{4}$, na perspectiva benjaminiana, sempre estão inacabados e se inserem num projeto intencionalmente fragmentado, e é nesse sentido, especialmente, que suas ideias se revelam como fonte metodológica inesgotável. Parafraseando Umberto Eco (1986), a proposta de Benjamin seria como uma "obra aberta", em que o autor "organiza uma seção de efeitos comunicativos de modo que cada possível fruidor possa compreender, na mencionada obra, a forma originária imaginada pelo autor" (p. 40).

Como obra aberta, atende a uma infinidade de atividades possibilitadoras. Permite iluminar o fazer social, pensar realidades contraditórias, enxergar uma cadeia de eventos na sua especificidade etc. No campo da psicologia social, Walter Benjamin ainda tem muito a contribuir, tanto como pensador da história quanto da narrativa e da experiência dos atores envolvidos nos fenômenos sociais.

\section{Narrativa e memória}

A narrativa de história de vida, como metodologia utilizada na psicologia social, tem início no ato de uma conversa livre e simples, como aquelas entre amigos que se encontram fortuitamente. Nela, a história deve ser contada de forma despretensiosa, diferentemente do relato da grande história que tecem os grandes acontecimentos e que se caracteriza pelo aspecto catastrófico, acumulando

4 Benjamin enxerga, nos objetos do cotidiano, que podem ser tanto uma lâmpada quanto uma montanha, meios que comunicam. Esses objetos apelam ao homem para que este as nomeie. Assim, nasce em Benjamin um "novo materialismo", "um fascínio pelos objetos e pela materialidade do mundo" (Felinto, 2013, p. 11). incessantemente "ruína sobre ruína"s (Benjamin, 2012, p. 246). Com certo apelo saudosista, Benjamin sente falta das histórias que ouvia sua mãe contar quando ficava febril: "Eu as amava", dizia ele, "pois da mão de minha mãe já gotejavam histórias que, logo, em abundância, emanariam de sua boca" (Benjamin, 2013, p. 75). Dizia que tais histórias lhe permitiram saber da sua origem: "A carreira de um parente antepassado, as regras de conduta de meu avô", (Benjamin, 2013, p. 75). De um lado, a história dura e material, como uma longa narrativa (ciência histórica), de outro, a requintada e espiritual, aquela que é capaz de restituir a memória e a lembrança dos acontecimentos. Contar histórias se relaciona a essa última realidade.

Compreender o processo contínuo de uma identidade só é possível quando o pesquisador apreende o sentido do acontecimento vivido, dentro de uma dinâmica de relação com os outros. Assim, é necessário apreender a memória e a lembrança do ocorrido a partir dos acontecimentos em que os fatos são descritos, de forma que:

o sujeito que narra é considerado uma totalidade que se manifesta na particularidade de uma história. Essa manifestação se dá na dinâmica da narrativa na qual o narrador não utiliza para se definir, atributos ou características, mas relata atividades, representações, relações com os outros, assim como revela sentimentos, angustias, alegrias etc., mergulhados e eclodidos nas relações no mundo, no desempenho da atividade. (Alves, 2017, p. 35)

Aquele que conta uma história faz nascer, naquele que a ouve, um conhecimento que se perdera no tempo da própria trajetória, e o que traz à tona essa história é a rememoração, com seu potencial de fazer alguém se apoderar não propriamente de um passado, mas do presente mesmo, uma vez que a história deve ser carregada do sentido de um "agora" (Jetztzeit). Esse "agora", para Benjamin, é comparável ao tempo dos calendários que, diferentemente do tempo dos relógios, celebra os mesmos acontecimentos como se fossem vividos no presente, o que o transforma em verdadeiro "monumento de uma consciência histórica” (Benjamin, 2013, p. 18). Esse dinamismo possibilita compreender a história como uma teoria da memória, que precisa ser escavada se quiser ser encontrada. Essa ideia surgiu, para Benjamin, por assim dizer, "debaixo das cobertas", como em um jogo de esconde-esconde infantil: "rastejava lá para dentro, puxava a coberta por cima da cabeça e voltava o ouvido na direção dessa garganta escura, alimentando de vez em quando o silêncio com palavras que regressavam em forma de histórias" (Benjamin, 2013, p. 75).

\footnotetext{
5 Segundo Callado (2006), Benjamin compreende ruína como um "amontoado de valores falsificados, paradigmas, normas e códigos vazios" (p. 78), ao mesmo tempo em que é metáfora para a multidão de deserdados pelo pensamento iluminista.
} 
A memória pode se perder na experiência mesma, quando a vida moderna impõe seu ritmo sem deixar tempo para partilhas de histórias de vida; em decorrência, o conteúdo simbólico dessa memória começa a correr o risco de permanecer oculto. Nesse caso, a função daquele que ouve o relato de uma experiência ou a narrativa de sua história é o de restituir o caráter simbólico da palavra, impregnado de autoconhecimento. Desse modo, a rememoração recupera, antes de tudo, a percepção primordial (Benjamin, 2011, p. 13), a imagem que se tinha da experiência no exato momento do ocorrido. Como trazer de volta esse conteúdo simbólico? Nomeando, uma vez que a palavra falada reclama de novo os seus direitos de nomeação (Benjamin, 2011). Esse momento de rememoração é compreendido por Benjamin como um retorno a um estado paradisíaco, referindo-se ao paraíso terrestre de Adão e Eva. Esse é o lugar da renovação da palavra e das ideias, e nessa renovação "reconstitui-se a percepção original das palavras" (Benjamin, 2011, p. 14). Em Das passagen-werk (1927-1940), memória e despertar estão intimamente relacionados (Benjamin, 2017), de modo que conseguir viver o presente é como um "acordar de um sonho" (p. 591).

Ao retomar o debate sobre os estudos de identidade que utilizam a narrativa de história de vida, como método de pesquisa, observa-se que o entrevistado, comumente, tem sido mobilizado por questões amplas, como "quem sou eu?", com o objetivo de desencadear uma narrativa. Ciampa (1987), em A estória do Severino e a história da Severina, considera que, na narrativa de uma história de vida, o pesquisador (ouvinte) pode captar o aspecto representacional da noção de identidade (enquanto produto), assim como o aspecto constitutivo, de produção.

Compreender essa relação dialética entre o narrado e a sua produção, na perspectiva abordada por Benjamim sobre memória e despertar, nos leva a pensar que, no ato da narrativa, ocorre uma renovação no sentido de que a memória do vivido no passado se reconstrói no presente.

\section{Relato}

As histórias, no momento em que são contadas, se apresentam desconexas do sentido de tempo e espaço, são como colchas de retalho que precisam ser "montadas" para só então serem transformadas em algo memorável, "relatável". Para que isso aconteça, essas histórias precisam criar forma em um lugar, um espaço cênico determinado, é nesse espaço que a história contada vai se configurando, ganhando corpo. Walter Benjamim (2011) evoca o ambiente das cortes reais do século XVII, onde a intimidade espacial diminuía a distância entre as pessoas, fator que se revelava decisivo para o ato de "montagem de tudo o que é memorável" (p. 59). Dentro de um espaço assim, que convida à intimidade, a história se desloca e se espalha como as sementes no solo e conduz a um estado paradisíaco, fora até do próprio tempo (Benjamin, 2011). "Fora do tempo" não no sentido de "fuga" do tempo histórico ou de busca de um lugar diverso daquele em que se está, mas como um tempo no qual se deixou marcas e que incita o contador de histórias a recordar de si mesmo ou de algum acontecimento memorável, a exemplo das paisagens típicas do Barroco. Na tendência barroca, segundo Benjamin (2011), a fuga do mundo não se dá com uma antítese entre história e natureza, mas "na total secularização do histórico no estado criatural" (p. 55).

Contar uma história e ouvir um relato, a partir do que foi dito, parece simples. No entanto não é assim; ou porque as pessoas, com o tempo, perderam a capacidade de contar suas histórias ou porque quem ouve, de fato, não sabe ouvir. Aquele que conta sua história espera do ouvinte não somente que este o auxilie na já árdua tarefa da rememoração de seu sofrimento, mas, sobretudo, que o ajude, a partir do relato, a fazer uma "reparação das injustiças passadas e a realização da utopia social" (Löwy, 2005, p. 50).

O relato de uma história está diretamente relacionado com a descrição de uma experiência, e esse fato, por si só, é o que o diferencia de outros tipos de fala. O relato não apenas serve para rememorar, mas principalmente para curar a humanidade fraturada, sofrida e ferida representada em um indivíduo único e inconfundível. Por outro lado, pelo próprio fato de que contar uma história se relaciona com viver uma experiência, esse ato pode ser um processo penoso e, em alguns casos, impossível, como quando se passou pela experiência de um acontecimento traumático. Nesse caso, não se consegue, simplesmente, pôr em palavras a própria história de vida, uma vez que situações estressantes empobrecem a capacidade de relatar determinada experiência. Benjamin recorda os jovens que retornaram da guerra. Definitivamente, eles não eram os mesmos de quando partiram. Jovens que há pouco iam conversando alegres pelo caminho em direção à escola, agora voltavam mudos do campo de batalha, "numa paisagem em que nada permanecera inalterado, exceto as nuvens e, debaixo delas, num campo de forças de torrentes e explosões destruidoras, o frágil e minúsculo corpo humano" (Benjamin, 2012a, p. 214).

A narrativa da própria história pode ser comparada com alguém que empreende uma viagem. No alemão, Erfahrung (experiência) se origina do radical Fahr, no sentido literal de percorrer, de atravessar uma região durante uma viagem (Gagnebin, 1994). Quem viaja muito tem muito o que contar (Benjamin, 2012a). A "experiência", portanto, no sentido benjaminiano, tem em sua origem a ideia de algo dinâmico, capaz de passar de uma pessoa para outra enquanto os dois empreendem uma caminhada: "A experiência que passa de boca em boca é a fonte a que recorreram todos os narradores. E, entre as narrativas escritas, as melhores são as que menos se distinguem das histórias orais contadas pelos inúmeros narradores anônimos" (Benjamin, 2012a, p. 214).

Da maneira como foi empregada, erroneamente se pode pensar que a noção de experiência, para Benjamin, 
teria surgido no vocabulário do crítico e filósofo tão facilmente quanto como um andar despreocupado. No entanto esse tema, além de ter sido amadurecido ao longo de várias etapas ${ }^{6}$, muito longe de significar mera transmissão de uma vivência ou uma tradição, carrega força política, social e antropológica, além de servir como crítica à própria noção de experiência. Nos primeiros escritos de 1913, o então jovem Benjamin, integrado ao movimento jovem berlinense, os Estudantes Livres, compara a experiência dos mais velhos ao "Filisteu", imagem bíblica que refere ao gigante filisteu (adulto) que luta contra o esquelético Davi (jovem) ${ }^{7}$ :

Nosso combate por uma questão de responsabilidade está sendo travada contra um ser mascarado. A máscara dos adultos é a "experiência" (Erfahrung). É uma máscara inexpressiva, impenetrável, sempre igual a si mesma. Esses adultos já viveram de tudo: juventude, ideais, esperanças, mulheres. Tudo resultou ser uma ilusão (Benjamin, 1993, p. 93)

Benjamin buscava um conceito de experiência que fosse total, integral, de modo que aquilo que os adultos costumavam apresentar como experiência não servia por não ser genuíno. Os adultos, em sua opinião, ao evocarem uma "experiência" sem expressão e insensível às coisas mais simples da vida, só o que conseguem fazer é constranger os jovens, impedindo-os de buscarem o novo nas próprias experiências. Nos textos de 1930, a questão da experiência é retomada por Benjamin ao lembrar que o mundo moderno e capitalista enfraquece a experiência ao mesmo tempo em que valoriza a Erlebnis, a vivência privada do sujeito solitário. Em O Narrador e Experiência e Pobreza, a verdadeira arte de contar histórias depende da transmissão de uma experiência em seu sentido mais pleno. As vivências, pela sua própria natureza, "são esvaziadas, privadas de substância” (Benjamin, 2006, p. 370, J 54,7).

Ao relatar sua história, a pessoa está em busca não somente da sua capacidade de rememorar (Eingedenken) um acontecimento, mas também de redimi-lo (Erlösung). Essas noções, em Walter Benjamin, estão relacionadas com

6 De fato, cinco ensaios de Walter Benjamin, em diferentes datas, evidenciam como o tema foi amadurecendo, de modo que até se pode falar em "experiências", e não uma única "experiência" em Benjamin. Os cinco ensaios nos quais desenvolve essa ideia são, em ordem cronológica: Experiência (1913); Sobre o programa da filosofia do porvir (1918); Experiência e pobreza (1933); O narrador (1936); Sobre alguns temas baudelairianos (1940). Apenas no último, em vez de Experiência, utiliza a palavra Vivência (Erlebnis).

7 No relato bíblico, Golias, o filisteu, de dois metros e noventa centímetros, vestiu-se para a batalha: "usava máscara de bronze e vestia couraça que pesava sessenta quilos" (I Sam. 17 - Bíblia Tradução Ecumênica, 1977). $\mathrm{O}$ homem gigante desafiou os filhos de Israel para que o enfrentassem. Quando viram o homem, fugiram, cheios de medo. Davi, ao contrário, se ofereceu para enfrentar o filisteu. Seus compatriotas o vestiram para a luta, mas a armadura era pesada demais para ele e, assim, simplesmente despiu-se da máscara e da couraça. O relato continua mostrando que o gigante filisteu, ao ver aquele menino magricela, riu-se dele, pois, enquanto o guerreiro experiente entrava vestido para o combate, Davi, sem experiência de guerra, empunhava pedras e uma atiradeira. os dois problemas envolvendo a experiência já mencionados, ou seja: perdemos nossa capacidade de contar histórias e, por isso, as esquecemos, mas também não sabemos mais ouvi-las. Benjamin utiliza o verbo zu vergessen (esquecer) no sentido de "erradicar da consciência", "não se aperceber", "não prestar atenção" ou simplesmente deixar coisas passadas no passado (Ulrich, 2001, p. 4).

Por outro lado, há coisas que se tenta esquecer, mas simplesmente não se consegue facilmente. Benjamin lembra, nesse sentido, a experiência da guerra. As tropas do III Reich e os bunkers continuariam a assombrar a memória e a frustrar os esforços para esquecer esses tristes acontecimentos. No verbo zu vergessen há, além da ideia de um esquecer no sentido de reconhecer o que se viveu, também o sentido de neutralizar (Ulrich, 2001) a força de um acontecimento passado no presente. Neutralizar não no sentido de negar, mas de ver, na experiência traumática do passado, vários níveis de sentido e receber, desse objeto do passado, "o impulso para um arranque constantemente renovado" (Benjamin, 2011, p. 8).

Portanto saber ouvir é saber compreender, do outro, a sua experiência, que não se reduz a mero relato de "vivências". Walter Benjamim diferencia "experiência" de "vivência" e, para ilustrar essa diferença, o filósofo recorda uma fábula muito conhecida de sua geração, "O velho vinhateiro", que fala de um homem idoso em seu leito de morte que, percebendo que seu fim se aproximava, reuniu os filhos e lhes "legou uma experiência". Com a lenda, Walter Benjamin sublinha o valor e a importância da tradição que a modernidade, aos poucos, foi solapando. Conforme mencionado, o homem ou mulher, avançados em idade, podem passar uma experiência, e não uma simples vivência, e o fazem quando "são capazes de contar uma história como deve ser" (Benjamin, 2012a, p. 85).

A vivência, por sua vez, não estaria necessariamente ancorada na tradição, como a experiência, justamente por seu caráter mais informativo, marcado pela brevidade, como a notícia do jornal, que simplesmente fornece uma informação, e não uma experiência no sentido benjaminiano. Além disso, a notícia tende a tolher a imaginação do leitor por fornecer todas as informações que ele julga necessárias. Da mesma forma, aquele que escuta uma história de vida deve tomar cuidado em não recolher, daquele que a conta, a notícia, mas a experiência, com o risco de fazer o próprio relato diminuir a força desta última:

Na substituição do antigo relato pela informação e desta pela sensação reflete-se a crescente redução da experiência. Todas essas formas, por seu lado, destacam-se da narrativa, que é uma das mais antigas formas de comunicação. Para ela, não era importante transmitir a pura objetividade do acontecimento, como faz a informação; integra-o na vida do contador de histórias para passá-lo aos ouvintes como experiência. Por isso, o contador de histórias deixa na experiência as suas marcas, tal 
como o oleiro deixa as das suas mãos no vaso de barro. (Benjamin, 2015, p. 100)

A história contada, para Benjamin, deve ter a garantia de que será amparada por uma força redentora (Erlösung), ideia que vai buscar na teologia judaica e se liga diretamente, na língua alemã, ao evento ou acontecimento (Ereignis), fato que fornece ao termo um caráter messiânico. Löwy (2005), ao comentar esse termo, diz que ele se refere, em primeiro lugar, a uma felicidade pessoal como resultado da redenção do próprio passado, "a realização do que poderia ter sido, mas não foi”. A redenção, portanto, aconteceria como um momento particular que irrompe no tempo linear. Estudando a questão do messianismo na Carta de São Paulo aos Romanos, Giorgio Agamben (2016) afirma que esse tempo nutre outro tempo que conjuga memória e esperança, passado e presente, plenitude e falta, origem e fim. Ainda, para o autor, a redenção, no sentido paulino, acontece com a chegada do Messias, que fará os fracos e sem importância, que, afinal, não existem de fato, prevalecerem sobre aqueles que o mundo considera fortes e importantes.

A modernidade, na opinião de Benjamin, gradualmente nos fez perder a capacidade messiânica e redentora do falar e do ouvir. Na sua segunda tese "Sobre o conceito de história" (Benjamin, 2012a), afirma que o passado tem um ímpeto à redenção e, quando falamos de algo que nos aconteceu, damos voz àqueles que nos precederam, mas que conosco se ligam através de uma história e memória comuns. Nossos antepassados, de uma maneira ou outra, passaram pela nossa vida, viveram a mesma experiência. Portanto naquela voz que ouvimos, nas palavras que deixamos livremente fluir, damos eco àquelas que já emudeceram. $\mathrm{O}$ apelo dessas vozes que querem ser ouvidas "não pode ser rejeitado impunemente" (Benjamin, 2012a, p. 242). Nesse sentido, há uma estreita conexão entre o sujeito e a humanidade. $\mathrm{O}$ indivíduo redimido redime a humanidade toda e, em consequência, "somente a humanidade redimida obterá o seu passado completo" (Benjamin, 2012a, p. 242).

A partir dessa concepção de Benjamin sobre a estreita conexão o entre o sujeito e a humanidade ocorridos na narrativa, pode-se pensar que o relato de experiências vividas, fundamentalmente, revela as metamorfoses ocorridas e possibilitadas, na referida conexão, no processo dinâmico e histórico da identidade.

\section{A Erfahrung e a "escuta do outro"}

A narrativa de história de vida pode facilmente permanecer restringida ao mero registro de recordação de um passado distante, nostálgico sem, contudo, conseguir operar qualquer movimento, qualquer ação ou mudança ${ }^{8}$.

8 Agamben (2012), recorrendo a Aristóteles, mostra que ambas, a experiência e a poiésis, se relacionam com um "fazer humano", porém não um "fazer" como em geral entendemos, legado do latim, no sentido de operar algo com as mãos. O "fazer" artístico é de uma natureza diferenciada, que entre os
Isso pode acontecer quando se deseja ouvir de alguém o relato de sua experiência e, no entanto, o que se tem é outra coisa, o relato de uma vivência, apenas. Essa confusão acontece especialmente porque uma vida exposta a sofrimentos e às rápidas transformações do mundo e seu incremento das relações fetichizadas, estabelecidas em nossa existência cotidiana, privam os sujeitos de suas biografias, empobrecendo o relato de uma autêntica experiência. "O homem moderno", segundo Agamben (2014), "volta para casa à noitinha, extenuado por uma mixórdia de eventos - divertidos ou maçantes, banais ou insólitos, agradáveis ou atrozes -, entretanto nenhum deles se tornou experiência" (p. 22). Essa realidade, em última instância, é o que impede o homem de "traduzir-se em experiência" (Agamben, 2014, p. 22).

Para evitar que isso aconteça, é necessário não perder de vista o real sentido da transmissão da experiência para uma efetiva escuta do outro. Nesse sentido, é preciso ficar atento a algumas condições a fim de que a escuta privilegie aqueles dados que se baseiam na experiência genuína do sujeito. À luz do pensamento de Walter Benjamin, pode-se prever as condições que serão elencadas nos subtópicos a seguir.

\section{Perceber o "tempo da representação" e o "tempo representado"}

O tempo do sujeito que relata sua história é o tempo de agora que, em termos de caducidade e ruína, não se diferencia muito dos tempos nos quais viveu Benjamim. O importante não é simplesmente "arrancar" de um passado vivido o ocorrido, mas, acima de tudo, fazê-lo saltar (sprunghaft). "Não é", como afirma Benjamin (2006), "que o passado lança sua luz sobre o presente ou que o presente lança sua luz sobre o passado" (p. 504); o que importa, na verdade, é saber se o ocorrido "encontra o agora num lampejo" (p. 504, N 2a, 4). Isso implica em dizer que o relato de determinada experiência deve sempre operar uma dialeticidade, isto é, no instante mesmo do relato acontece a possibilidade de o passado colocar o presente numa condição crítica, o que Benjamin (2006) denomina de "agora da cognoscibilidade" (p. 505, N 3,1).

Por outro lado, capturar o tempo da experiência não é tarefa tranquila. Em primeiro lugar, porque o mundo da experiência e das vivências corre em alta velocidade, pondo a memória em fuga e imprimindo o tempo na transitoriedade, na continuidade, sem muitos sobressaltos. Em segundo lugar, porque somos quais sonâmbulos andando pela vida, sem percebê-la de fato. A seu turno, aquele que ouve atentamente não faz outra coisa senão despertar o outro de um sono profundo, é aquele que "mobiliza a vida inteira em seu ponto de

gregos era denominado de práxis, que se origina de Praxo - "eu atravesso". A palavra que mais se assemelha à práxis grega é "experiência" (do latim Experientia), que, em seu sentido mais literal, significa "ir da ação na ação". Em grego, "experiência" é Empeiria, que, contendo a palavra práxis, tem o mesmo sentido etimológico de "ir da ação na ação". 
ruptura" (Benjamin, 2006, p. 506, N 3a, 3; N 4,1), que assume a tarefa da interpretação dos sonhos.

O tempo da representação evocado deve ter, portanto, um lócus no tempo representado, no hoje, no agora da cognoscibilidade, de forma que:

cada fato histórico apresentado dialeticamente se polariza, tornando-se um campo de forças no qual se processa o confronto entre sua história anterior e sua história posterior. Ele se transforma neste campo de forças quando a atualidade penetra nele. E assim o fato histórico se polariza em sua história anterior e posterior sempre de novo, e nunca da mesma maneira. (Benjamin, 2006, p. 512, N 7a, 1)

"Nunca da mesma maneira", é sempre bom ressaltar. Para que isso aconteça, é importante que a história contada seja "destruída", uma vez que "a construção pressupõe a destruição" (Benjamin, 2006, p. 512, N 7,6). A experiência, antes de ser relatada, precisa passar por um processo de depuração e de distanciamento do caráter fetichista do espaço onde a experiência aconteceu. Não só ela, mas também as vivências, que podem ser transformadas em experiências em seu sentido pleno, num processo em que a atenção se concentra para apreender os detalhes da vida. "O homem", como afirma André Breton (1924), um sonhador, "cada dia mais desgostoso com seu destino, a custo repara nos objetos de seu uso habitual, e que lhe vieram por sua displicência, ou quase sempre por seu esforço, pois ele aceitou trabalhar, ou pelo menos, não lhe repugnou tomar sua decisão" (p. 1).

\section{Reconhecer o outro como "sujeito", e não simplesmente como "objeto" da linguagem}

Pode-se incorrer no erro de aproximar-se do sujeito tão somente a fim de retirar dele "matéria" para a pesquisa. A experiência do sujeito pertence unicamente a ele, que a "empresta" a quem quiser. Falando da Criação, conforme o relato bíblico do livro de Gênesis, Benjamin enfatiza o fundamento linguístico do ato criador. No paraíso, o homem é convidado a participar do ato criador, nomeando os seres recém-criados. "Nomear", no sentido bíblico, significa "possuir"; porém, mais que nomear, significa também estar aberto à receptividade da natureza espiritual das coisas, de forma que, ao nomear, deve-se alcançar uma "transcendência do que é falado" (Hasenheit, 2003, p. 23). Dessa forma, ao falar de experiências que são suas, o sujeito utiliza uma linguagem que parecerá sempre como um enigma para aquele que a recebe, pois, na verdade, o sentido das coisas não nasce tanto da presença, mas da ausência dos objetos, ausência tornada presente na linguagem (Pires, 2014). Agamben (2012) resume esse momento, do estranhamento da experiência do outro, a princípio incompreensível e que só se torna compreensível se aceitar entrar "no círculo da absoluta perversão" (p. 54):

Se o espectador consente ao radical estranhamento dessa experiência e, deixando para trás todo conteúdo e todo suporte, aceita entrar no círculo da absoluta perversão, ele ... não tem outro modo de se reencontrar senão assumindo integralmente a própria contradição. Isto é, deve dilacerar a própria dilaceração, negar a própria negação, suprimir o seu ser suprimido; ele é absoluta vontade de ser outro e o movimento que divide e, ao mesmo tempo, reúne a madeira que se descobre violino e o violino, o cobre que acorda clarim e o clarim; e, nessa alienação, se possui e, possuindo-se, se aliena. (Agamben, 2012, p. 54)

\section{A dialética da escuta}

A escuta do outro por meio de sua experiência sempre será concebida a partir de uma relação dialética que nasce de uma situação na qual o social sofre fissuras e imagens fetichizadas que, a princípio, até dão a impressão de aliviar as fraturas da existência e oferecer felicidade, fatos que não resistem a uma crítica dialética e que se mostram, no fundo, como uma "felicidade perversa". Habermas (2011, p. 44), a esse respeito, afirma que "o dialético não é a própria intersubjetividade sem coerções, mas a história de sua opressão e de seu restabelecimento". A experiência dialética, dessa forma, assume uma característica peculiar, de "dispor a aparência do sempreigual" (Benjamin, 2006, p. 515, N 9,7) na história. No entanto tal processo não pode ser confundido com a ideia de progresso, pois, na medida em que o progresso avança, pode-se ter a falsa impressão de que as coisas estão mudando. Contudo no progresso não há ruptura ou descontinuidade e, portanto, as coisas continuarão sendo as mesmas. "A ideia de um progresso da humanidade na história", afirma Benjamin (2012b) na sua tese 13, "é inseparável de sua marcha no interior de um tempo vazio e homogêneo" (p. 17). Nas Passagens, afirma:

Existe uma experiência da dialética totalmente singular. A experiência compulsória, drástica, que desmente toda "progressividade" do devir e comprova toda aparente "evolução" como reviravolta dialética eminente e cuidadosamente composta, é o despertar do sonho ... O método novo, dialético, de escrever a história apresenta-se como a arte de experienciar o presente como o mundo da vigília ao qual se refere o sonho que chamamos de o ocorrido. Elaborar o ocorrido na recordação do sonho! Quer dizer: recordação e despertar estão intimamente relacionados. O despertar é, com efeito, a revolução copernicana e dialética da rememoração (Benjamin, 2006, p.434, K 1,3) 
Uma verdadeira experiência dialética, portanto, deverá operar em duas frentes: antes de tudo, deverá fornecer para o sujeito uma oportunidade de operar a ruptura que será, para ele, sempre traumática, em contraposição ao sujeito fetichista, que trata de pacificar contradições que operam uma "negação da negatividade". Outro momento da experiência dialética deverá ser aquele que opera algo como um "despertar de um sono", que é como Benjamin simboliza a experiência em seu maior grau de intensidade. Ao falar desse "despertar", o filósofo tem em mente a cidade como matéria-prima de sua crítica. A cidade é múltipla e diversa, repleta de labirintos, com um número incontável de pessoas que se aglomeram, "com suas construções cinzentas, mercados cobertos, lojas de departamentos, exposições" (Benjamin, 2006, p. 435, K la, 5). Por outro lado, não é ao "mecanismo e maquinismo" que dirige sua crítica, mas "ao seu historicismo narcótico e à sua mania de se mascarar" (Benjamin, 2006, p. 436, K 1a, 6), tão peculiares do capitalismo de onde Benjamin afirma provir esse "sono repleto de sonhos" (p. 436, K 1a, 8).

Desde o início dos escritos em Passagenarbeit, as multidões aparecem retratadas como se estivessem dormindo, como em um torpor coletivo, de maneira que o marco principal da cidade moderna é a experiência do anonimato cercado de grande número de pessoas que se evitam e não se percebem. A multidão, em suma, se torna o "lugar escondido" da modernidade (Gilloch, 1996), mais propício para vivências (Erlebnis) que para experiências (Erfahrung).

Benjamin articula o processo da transformação da Erfahrung em Erlebnis quando a experiência fica reduzida a uma série randomizada de meias-impressões entre as pessoas. Agindo assim, elas são capazes de destruir a experiência integrada e coerente, tornando-se indiferentes, o que as faz sucumbir ao esquecimento e ao torpor, além de um imperturbável encontro com os outros (Benjamin, 2006).

A escuta, por outro lado, assume um caráter de negação quando se estabelece uma recusa à comodidade de passar despercebido e anônimo ou de passar pelo outro sem percebê-lo e, daí, sem que seja preciso reconhecê-lo. Benjamin (2015) destaca o momento em que Baudelaire é tomado de uma súbita paixão por uma mulher entre a multidão, cuja única preocupação é apenas a de abrir caminho por entre a multidão. $\mathrm{O}$ olhar mais detido e demorado permite perceber, no meio da multidão, um indivíduo, alguém que se diferencia dos demais, o que só é possível quando alguém é despertado pelo amor:

A rua ia gritando e eu

ensurdecia.

Alta, magra, de luto, dor tão

majestosa,

Passou uma mulher que, com

mãos sumptuosas,

Erguia e agitava a orla do vestido;
Nobre e ágil, com pernas

iguais a uma estátua.

Crispado como um excêntrico,

eu bebia, então,

Nos seus olhos, céu plúmbeo

onde nasce o tufão,

A doçura que encanta e o

prazer que mata. (Benjamin, 2015, p. 38)

A mulher representa a "figura do choque", que atinge o sujeito no cerne da sua emoção, muito embora, como acontece em uma grande cidade, esse que parece ser um amor à primeira vista é, na verdade, "um amor à última vista", pois o poeta nunca mais a viu, logo que ela desapareceu no meio da multidão.

Parar na grande cidade para ouvir o sujeito em sua narrativa é reconhecê-lo "por um olhar muito particular" (Benjamin, 2015, p. 110), é destacá-lo em sua individualidade e particularidade. A respeito do texto em prosa de Hoffman, Benjamin destaca a figura do paralítico que, sentado em sua varanda, observa a torrente da multidão. Ele está acima dessa multidão, próximo à sua janela. De um rompante, apanha seus binóculos de teatro. $\mathrm{O}$ uso desse instrumento, segundo Benjamin (2015), "corresponde perfeitamente à atitude interior do utilizador" que consiste no fato de "regozijar em observar" (p. 112). É fácil perceber como o observador, com seus binóculos, destaca uma cena entre as demais, volta toda sua atenção a um único quadro como o visitante de um museu, que elege uma pintura em particular e nela demora o olhar. Da mesma forma, o outro, que fala àquele que se dispõe a ouvir, representa uma figura que se destaca e que, sem deixar de ser integrante de um todo, que é a multidão das grandes cidades, é alguém que abre a possibilidade de contar uma experiência diversa dos relatos de vivências que se perdem com a multidão em fuga.

Nesse sentido, uma dialética da escuta tem menos a ver com o sistema hegeliano e mais com um caráter negativo e inapropriável da experiência no sentido de que a escuta inicia um "círculo de relatos", em que a experiência nunca pode ser dada como finalizada e que consiste em "ser sempre o que não é ainda" (Agamben, 2014, p. 44), em que a fala de si mesmo será sempre uma "experiência de morte" (p. 44). De fato, falar de um passado equivale a falar da experiência de um alguém que se foi e que agora, no momento da fala, já se sente como outra pessoa. Fala essa que, amanhã, de um instante para o outro e dentro desse círculo dialético de negatividade constante, poderá inscrever uma experiência renovada em um tempo sempre novo, dado que, muito mais que relembrar, trata-se sempre de destruir (as aparências ilusórias), para só então reconstruir (outra possibilidade de realidade), como fazem as crianças e artistas. Segundo Gagnebin (2014):

Crianças e artistas se põem a experimentar com o mundo, isto é, a destruí-lo e a reconstruí-lo, porque não o consideram como definitivamente dado. Essas brincadeiras essenciais implicam uma noção 
de ação política que não visa a transformação do mundo segundo normas prefixadas, mas a partir de exercícios e tentativas nos quais a experiência humana - tanto espiritual e inteligível como sensível e corporal - assume outras formas. (p. 175)

\section{Conclusão}

À luz do pensamento de Walter Benjamin, as narrativas de história de vida instauram uma nova relação entre os atores que falam, precisando o lugar que deve ser ocupado pelas partes envolvidas. De fato, a ação de ambos deve ser permeada pela noção de respeito e reconhecimento recíproco; juntas, essas ações apontam para a existência de feridas abertas e de injustiças impetradas. Tais feridas se revelam, sobretudo, pelo fato de o indivíduo não se ver reconhecido na própria autocompreensão, como refere Honneth (2010), para quem a atitude positiva que o sujeito tem de si tem início no confronto consigo mesmo e, quando isso acontece, pode contar com o reconhecimento afetivo do outro, com sua simpatia, seu tempo para a escuta.

Ciampa (1987), ao escutar a história da Severina, busca captar o sentido que o presente narrado traz do passado vivido e do projeto anunciado. É no presente que o que foi e o que planeja ser se manifesta através da narrativa, e esta, por sua vez, possibilita tornar visível o estar sendo, numa sucessiva exposição de personagens que desempenham papéis sociais.

A escuta, por outro lado, pode simplesmente ser reduzida à formulação e à emissão de juízo sobre o outro (Butler, 2017) se não se levar em conta que o momento da fala nunca expressa exatamente o si-mesmo vivente, e que o tempo do discurso não é o mesmo tempo da vida (Butler, 2017). Esse é um pré-requisito a se considerar antes de empreender uma escuta autêntica.

Benjamin acredita que a cidade, repleta de pessoas andando de um lado para outro sem tempo e sem prestar atenção nos rostos que passam à sua frente, como aquelas imagens em looping, não passam de uma série interminável de mesmos e desconhecidos rostos e, assim, a cidade, em seu movimento, cai em torpor que se manifesta como uma espécie de mimese da morte. "É impossível", completa Benjamin (2000), "não ficar emocionado com o espetáculo desta população doentia, que engole a poeira das fábricas, que inala partículas de algodão, que deixa penetrar seus tecidos pelo alvaiade, pelo mercúrio e por todos os venenos necessários à realização das obras-primas" (p. 11).

Em seu conceito de história, Benjamin se inspira no historiador positivista Fustel de Coulanges e faz uma revisão do termo empatia (Einfühlung) ou, mais bem traduzido, “identificação afetiva”. A história, por muito tempo, teve empatia com o vencedor e serviu de instrumento das classes dominantes. Benjamin propõe "escovar a história a contrapelo", isto é, começar a contar a história desde o ponto de vista dos vencidos, dos excluídos, dos párias (Löwy, 2005, p. 79). Escutar uma história, interessar-se por ela como um valor, se transforma, assim, em uma postura oposta à sociedade cujo valor primordial se assenta no lucro financeiro, que reifica e precifica a vida. Em um cenário como o que estamos acostumados, é fácil confundir a pergunta sobre quem alguém é por um vocabulário equivocado que diz o que alguém é (Arendt, 2007).

Walter Benjamin aponta, portanto, para uma escuta na qual a transmissão da experiência ganha seu sentido pleno: ouvir sem pressa, identificar-se afetivamente com aquele que relata sua história, não escutar como quem escuta uma notícia, mas como quem, ao contar sua história, deixa marcas e ensinamentos para as gerações futuras.

Finalmente, é necessário ter consciência de que a pessoa que relata sua experiência espera ser redimida dos sofrimentos que foram despertados enquanto acontece a fala. E cabe ao pesquisador de identidade, que utiliza a narrativa como instrumento metodológico, uma escuta que exige um interesse pela história narrada que transcende os valores do mundo sistêmico e se constitui, enquanto ouvinte sensível à percepção do outro, capaz de captar o sentido atribuído pelo narrador, assim como as metamorfoses ocorridas ao longo da narrativa. Neste sentido, o pesquisador tem como objetivo apreender o sentido da história ouvida e contar como se processou as metamorfoses da identidade expressa na dinâmica das personagens que desempenharam vários papéis sociais. Desse modo, o pesquisador também se revela como um narrador que conta o que ouviu, redefinindo a narrativa a partir da sua escuta, prenha de conceitos, mas fundamentalmente com consciência de que relata, além da experiência do outro, a experiência da relação que ocorreu entre o narrador e o ouvinte.

\title{
The story of life according to Walter Benjamin: contributions to identity studies
}

\begin{abstract}
Life history reports are not, as many people think, a methodology of easy application, at least when taking into account the thought of Walter Benjamin for whom history is not a simple account of facts, but a chain of experiences that may not always be expressed without taking risks which to a great extent undermine or violate the conscience of the individual who makes the report a means of finding "redemption" (Erlösung) from experiences of the past marked by suffering. Added to this is the fact that, according to the author, with Modernity, the capacity of both counting and listening to life experiences has been lost. This paper discusses such matters and contributes to studies on identity from the perspective of critical social psychology, which uses the method of History of Life Report.
\end{abstract}

Keywords: memory, experience, redemption, identity. 


\section{L'histoire de vie à la lumière de la pensée de Walter Benjamin : apports aux études sur l'identité}

Résumé: L'histoire de vie n'est pas, comme beaucoup le pensent, une méthodologie d'application facile, du moins en tenant compte de la pensée de Walter Benjamin, pour qui l'histoire n'est pas un simple récit de faits, mais une chaîne d'expériences qui ne peut pas toujours être exprimé sans prendre des risques qui portent, en grande partie, atteinte à la conscience de l'individu qui fait du rapport un moyen de retrouver la « rédemption » (Erlösung) d'expériences passées marquées par la souffrance. À cela s'ajoute le fait que, selon l'auteur, avec la modernité, la capacité de raconter et d'écouter des expériences de vie a été perdue. Le texte aborde ces questions et cherche à contribuer aux études sur l'identité, dans la perspective de la psychologie sociale critique, qui utilise la méthode du Rapport d'Histoire de vie.

Mots-clés: mémoire, expérience, rédemption, identité.

\section{El relato de historia de la vida a la luz del pensamiento de Walter Benjamin: Contribuciones a los estudios sobre identidad}

Resumen: El relato de historia de vida no es, como muchos piensan, una metodología de fácil aplicación, al menos teniendo en cuenta el pensamiento de Walter Benjamin para quien la historia no es simple relato de hechos, sino un encadenamiento de experiencias, que no siempre pueden ser expresadas sin correr riesgos los cuales, en gran medida, perjudican o violan la conciencia del individuo que hace del relato un medio para encontrar la "redención" (Erlösung) de experiencias del pasado marcadas de sufrimientos. A ello se agrega el hecho de que, según el autor, con la modernidad se perdió la capacidad tanto de contar como de oír experiencias de vida. Este texto trabaja esas cuestiones, así como busca contribuir a los estudios sobre identidad, en la perspectiva de la psicología social crítica, que utiliza el método de relato de historia de vida.

Palabras clave: memoria, experiencia, redención, identidad.

\section{Referências}

Agamben, G. (2012). O homem sem conteúdo (2a ed.). Belo Horizonte, MG: Autêntica.

Agamben, G. (2014). Infância e história: destruição da experiência e origem da história. Belo Horizonte, MG: UFMG.

Agamben, G. (2016). O tempo que resta: um comentário à Carta aos Romanos. Belo Horizonte, MG: Autêntica.

Alberti, V. (1996). O que documenta a fonte oral? Possibilidades para além da construção do passado. Trabalho apresentado no Segundo Seminário de História Oral: um lugar de inserções, Universidade Federal de Minas Gerais, Belo Horizonte, MG.

Alves, C. P. (2017). Narrativas de história de vida e projeto de futuro no estudo do processo de identidade. Textos e Debates, (31), 33-41.

Arendt, H. (1968). Walter Benjamin: 1892-1940 (Introdução). In W. Benjamin, Illuminations: essays and reflections (pp. 1-58). New York: Schocken Books.

Arendt, H. (2007). A condição humana (10a ed.). Rio de Janeiro, RJ: Forense Universitária.

Benjamin, W. (1993). La metafísica de la juventud. Barcelona: Paidós.

Benjamin, W. (1994). A obra de arte na era de sua reprodutibilidade técnica (6a ed.). São Paulo, SP: Brasiliense.

Benjamin, W. (2000). A modernidade e os modernos ( $2 \mathrm{a}$ ed.). Rio de Janeiro, RJ: Tempo Brasileiro.
Benjamin, W. (2006). Passagens. Belo Horizonte, MG: Editora UFMG.

Benjamin, W. (2011). Origem do drama trágico alemão (2a ed.). Belo Horizonte, MG: Autêntica.

Benjamin, W. (2012a). Magia e técnica, arte e política: ensaios sobre literatura e história da cultura (8a ed.). São Paulo, SP: Brasiliense.

Benjamin, W. (2012b). O anjo da história (2a ed.). Belo Horizonte, MG: Autêntica.

Benjamin, W. (2013). Rua de mão única: infância berlinense, 1900. Belo Horizonte, MG: Autêntica.

Benjamin, W. (2015). Baudelaire e a modernidade. Belo Horizonte, MG: Autêntica.

Benjamin, W. (2017). Das passagen-werk: Die Strassen von Paris: Einer der grundlagentexte materialistischer kulturtheorie - Blic in die Jetztzeit des Spätkapitalismus [e-book]. Berlin: Musaicum Books.

Bíblia: Tradução Ecumênica. (1977). São Paulo, SP: Loyola.

Breton, A. (1924). Manifesto surrealista. Marxists Internet Archive. Recuperado de: https://bit.ly/2E2nT84

Butler, J. (2017). Relatar a si mesmo: crítica da violência ética. Belo Horizonte, MG: Autêntica.

Callado, T. C. (2006). Walter Benjamin: a experiência da origem. Fortaleza: EdUECE, 2006

Camargo, A. (1994). História oral e política. In M. M. Ferreira (Org.), História oral e multidisciplinaridade (pp. 75-100). Rio de Janeiro, RJ: Diadorim. 
Ciampa, A. C. (1987). A estória do Severino e a história da Severina: um ensaio de psicologia social. São Paulo, SP: Brasiliense.

Ciampa, A. C. (2012). Identidade. In S. T. M. Lane \& W. Codo (Orgs.), Psicologia social: o homem em movimento (pp. 58-75). São Paulo, SP: Brasiliense.

Eco, U. (1986). Obra aberta (4a ed.). São Paulo, SP: Perspectiva.

Felinto, E. (2013). Meio, mediação, agência: a descoberta dos objetos em Walter Benjamin. E-Compós, 16(1), pp. 1-15.

Gagnebin, J. M. (1994). Histoire et narration chez Walter Benjamin. Paris: L'Harmattan.

Gagnebin, J. M. (2014). Limiar, aura e rememoração: ensaios sobre Walter Benjamin. São Paulo, SP: Editora 34.

Gilloch, G. (1996). Mith and Metropolis: Walter Benjamin and the city. Cambridge, UK: Polity Press.

Habermas, J. (2011). Técnica e ciência como ideologia. São Paulo, SP: Unesp.

Hasenheit, K.-U. (2003). Gefährlich lesen: Walter Benjamin's theorie der erfahrung. Leiden: Grin Verlag.

Hobsbawm, E. (1997). Sobre história. São Paulo, SP: Companhia das Letras.

Honneth, A. (2010). Capitalismo e riconoscimento. Firenze: Firenze University Press.

Löwy, M. (2005). Walter Benjamin: aviso de incêndio. Uma leitura das teses "Sobre o conceito de história". São Paulo, SP: Boitempo.
Le Goff, J. (2001). A história nova. São Paulo, SP: Martins Fontes.

Maccali, N., Minghini, L., Walger, C. S., \& Roglio, K. (2013, 7-11 agosto). História de vida: uma possibilidade metodológica de pesquisar os aspectos subjetivos no processo de tomada de decisão. Anais do Encontro da Anpad, Rio de Janeiro, 37, 1-16.

Nogueira, M. L. M., Barros, V. A., Araujo, A. D. G., \& Pimenta, D. A. O. O método de história de vida: a exigência de um encontro em tempos de aceleração. Pesquisas e Práticas Psicossociais, 12(2), 466-485.

Pires, E. G. (2014). Experiência e linguagem em Walter Benjamin. Educação e Pesquisa, 40(3), 813-828.

Pusca, A. (2009). Walter Benjamin: a methodological contribution. International Political Sociology 3, 238-254.

Santos, A. C. A. (2005). Fontes orais: testemunhos, trajetórias de vida e história. Recuperado de https://bit.ly/3166Pqr

Ulrich, G. (2001). Unforgiving remembrance: the concept and practice of Eingedenken in Walter Benjamin's late work (Doctoral dissertation). University of Toronto, Toronto.

Recebido: 07/06/2019

Revisado: 07/06/2020

Aprovado: 02/08/2020 